\title{
Critical Elements of the Medical Device Administration
}

\author{
Naif B. Alsharari
}

\begin{abstract}
The vast growth of medical devices in recent years in both innovation and its overall marketplace has profoundly impacted the medical field. This paper analyzes the critical elements of the medical device administrative program and researches the impacts of the influences of the demonstrative imaging hardware industry. The outcomes have indicated that the medical device direction has not impacted or influenced rivalry or development inside the various classes in this industry. This paper contains recommendations comprising of selected strategies for control that separate among levels of potential hazards to purchasers in which the objective of achieving buyer assurance can be accomplished with fewer undesirable consequences for the controlled business.
\end{abstract}

Index Terms-Quality of Product; Design; Surgical Instruments; Industry; Development; Social Insurance.

\section{INTRODUCTION}

There is growing literature covering the background, technicalities, and functions of medical devices. The product evaluation stage indicates that some single use instruments were unfit for their designated purposes despite being $\mathrm{CE}$ (Conformité Européenne) CE Marking for Industrial Equipment and Products) marked. Similar problems have been observed with other reusable surgical instruments. The emergence of these problems has resulted in the suggestion that the current structure and operations pertaining to the regulation of medical devices require reassessment and modernization [1].

This paper utilizes new board information on purchaser provider exchanges and an auxiliary model to observationally break down the dealing and value separation in a therapeutic gadget device [2]. Medical devices marketed in the United States must satisfy Food and Drug Administration (FDA) standards of safety and effectiveness [3]. Therapeutic gadgets speak to a critical "hard" cost, with overall spending surpassing USD \$235 billion [4]. A national review researched the flow practices of reprocessing and reusing the single-utilized restorative gadgets in the Canadian intense care healing centers [5]. Medical devices are used at all levels of health care: hospital, nursing home, work place, home, and outdoors. They range from low risk and common (adhesive ban- doges) to high risk and rare (custom-built prosthesis) [6]. Hospitals do have legitimate scientific and marketing motives for using investigational medical devices [7]. Medical device industry was viewed by Jeanne Lenzer wear he appointed the wrong occupation title to Dr. Richard A Deyo in the subtitle going with his photo [7]. Bill Hawkins Medtronic's leader and CEO, has said that this is an essential choice that guarantees patients maintaining a fitting access to inventive, and life sparing treatments [8]. A review of data of usage has revealed that the devices' uses have never missed their intended objective. Moreover, the analysis has revealed that the normal time to process applications for clinical trials for medicinal gadgets is presently just 48 days [9].

\section{A. Medical Device}

It has been duly noted that that restorative gadget direction has not substantially influenced the rivalry or development inside set up item classes in this industry. This recommends, by picking techniques for directions that separate among the levels of potential hazards to customers. The objective of purchaser security can be accomplished with less undesirable consequences for the controlled business [10],[11]. However, it is important to note that the definition does permit a clear order as a restorative gadget in all cases. The MEDEV (Medicinal Devise) records have allegedly been distributed, which can be counseled only in the instances of uncertainty. These records are drawn up by specialists from the national and European powers who are worried with the presence and uses of restorative gadgets as they are legitimate all throughout Europe. Despite their legitimacy, they yet have no formal regulatory oversight [11]. Throughout the years, an extensive variety of propositions for gadget enactment have been exhibited to the Congress, yet none of these initiatives have increased any support and backing from the fellow legislators and their respective leaders and administrators [12]. More informational sources are expected to upgrade the investigation of restorative gadgets and their use in the study of disease transmission [13]. In 2016, after an underlying review by the FDA, there was a directive to classify ecigarettes as a therapeutic gadget. This was indeed challenged by a producer in court, and following the judicial review of the case, it reported that the US Court of Appeals ruled that they be classified and regulated as a tobacco item [14].

\section{B. Quality Standards}

We wear broaden the writing by deciding the standard endogenously, demonstrating that the augmentation of social welfare involves an expansion in the surplus accumulating to customers served by the low quality firms and a lessening in the excess of the rest of the shoppers [15]. In past explorations on the least quality norms (Leland, 1979; Shapiro, 1983) there has been an exhibition of the presence of a gathering of buyers who are more terribly off as an after effect of the MQS (Minimum Quality Standard) strategy [16]. An account of the pharmaceuticals regarding the quality level has been determined to impact the expenses of the Research and Development (R\&D) associated with the new item. With the objective to concentrate solely on the impacts of various 
national quality norms, there are two indistinguishable nations with indistinguishable customers that are expected [17]. The ideal $\mathrm{q}(\mathrm{t})$ will fulfill the same differential conditions as some time recently, aside from that the limit conditions are distinctive [18]. Subsidies for the review and experiments were provided by the IDSA (Infectious Diseases Society of America) and the other coordinating associations [19]. Nonetheless, if the nations are exceptionally disproportionate as for size, the market incorporation may adversely impact the welfare in the expansive nation [20].

\section{Equipment Design}

The present requirements for such an organic way to deal with gear configuration is best exemplified by the accompanying extracts from one of the building supporters to the symposium [21]. This incorporates Damon and Randall's initial Army-Air Force work, The Harvard School of Public Health distributions in the 1950's and the Anthropometry section in the Human Engineering Guide to Equipment Design in 1963 [22], [23]. The book has four parts in. expansion to its presentation and conclusions: Anthropometry and human [24]. In this reading and excerpt, the services are no less than an era in front of a large portion of the private industry, whose thought of the connected science has a tendency to be restricted for the uses pertaining to emergency treatment, the treatment of insignificant injury, and pre-vocation examinations [25]. Presently, the architects are starting to understand that different strains must be considered. For instance, the quantity of things the administrator must pay, the multifaceted nature of the solid coordination required, and also the more refined and precise examinations of the strong burdens required [26].

\section{Product Development}

After the responses to these and the scores of comparative inquiries have been found, the item designer is prepared to commence their work [27]. There is an over-dependence on coordinating instruments to share information that can keep offices from finishing their own duties and tasks [28]. Powerful item family administration and stage recharging methodically create progressive eras of business sector driven item stages that are the premise for an association's particular business offerings [29]. Numerous organizations have sustained successful achievements resulting in the encouragement of devising new-item improvements with the board of trustees, and such achievements and subsequent support and encouragement by high bodies unquestionably would be a strong force against any administration seeking to defer embracing such a structure in the event that it would guarantee comes about [30]. We found humble backing for the expectation that there are speedier improvement cycles that are existent when joined with certain authoritative practices. For example, the cross-utilitarian groups and the utilization of a cutting edge plan apparatuses, are connected with higher execution [31]. In the item improvement it is fundamental to have the ability to show that the level of dangers may differ amongst ventures. In addition, the peril of dissatisfaction is exceptionally overwhelming [32].

\section{E. Medical device regulation}

Restorative gadget direction must be enhanced to shield general wellbeing and guarantee that a high caliber of quality and structure emerge, be maintained and there will be successful advancements that achieve the overall betterment for impacted patients [33]. Despite the fact that expanded government contributions in therapeutic innovation comes from a desire to make up for disappointments of the restorative commercial center, the quick impact is to put more prominent basic leadership dependence upon formal examinations, administration, lawful systems, and legislative issues [34]. For this situation, an expansive distance across metal-on-metal aggregate hip substitutions was permitted to enter the worldwide business sector without any prior clinical studies to survey and determine their security and viability [35]. The degree and nature of any enactment must be deliberately considered. The Department of Health, Education, and Welfare has attempted to launch an exhaustive investigation of restorative gadget control devices [36],[37]. To start with, we wear offered a brief similar outline of therapeutic gadget direction in the United States and Europe [33].

\section{FACTORS OF MedicAl DeVICE}

\section{A. Additional Factors}

INDEPENDENT \& DEPENDENT VARIABLES

\begin{tabular}{|c|c|c|}
\hline & Independent Variable & Quote and Reference \\
\hline \multicolumn{3}{|c|}{ Independent Variable 1} \\
\hline 1. & Treatment Efficiency & $\begin{array}{l}\text { "In the intensity range of } 8 \text { to } 13 \text { at this } \\
\text { flow rate, breakdown in treatment } \\
\text { efficiency is indicated" [38] }\end{array}$ \\
\hline 2 . & Surgical Instruments & $\begin{array}{l}\text { "The net effect of the war on the } \\
\text { surgical instruments industry at Sialkot } \\
\text { was positive and the industry certainly } \\
\text { expanded both horizontally and } \\
\text { vertically" [39] }\end{array}$ \\
\hline 3. & Medical Development & $\begin{array}{l}\text { It is expected to be appreciative, in any } \\
\text { case, to be given a chance to put the } \\
\text { record straight in various regards with } \\
\text { respect to the motivations behind } \\
\text { VSO's in contribution in therapeutic } \\
\text { advancement in the Third World and } \\
\text { the general population wear planning to } \\
\text { enlist [40] }\end{array}$ \\
\hline & \multicolumn{2}{|l|}{ Independent Variable 2} \\
\hline & Performance Standards & $\begin{array}{l}\text { The International Finance Corporation } \\
\text { (IFC), a private area arm of the World } \\
\text { Bank Group, has begun to apply the } \\
\text { new Performance Standards on the } \\
\text { Social and Environmental } \\
\text { Sustainability to private sector projects } \\
\text { it finances in an emerging mark [41] }\end{array}$ \\
\hline & Safety Device & $\begin{array}{l}\text { "We felt that any anesthetist who } \\
\text { wishes to depend on a wellbeing gadget } \\
\text { ought to acclimate himself with its } \\
\text { properties and appropriateness for the } \\
\text { device and procedure that he is } \\
\text { utilizing and ought to watch that it will } \\
\text { in reality work agreeably" [42] }\end{array}$ \\
\hline & Medical Testing & $\begin{array}{l}\text { We feel that any anesthetist who } \\
\text { wishes to rely on upon a prosperity } \\
\text { device should adjust himself with its } \\
\text { properties and fittingness for the gadget } \\
\text { and for the system that he is using and } \\
\text { should watch that it will in actuality } \\
\text { work pleasingly [43] }\end{array}$ \\
\hline & \multicolumn{2}{|l|}{ Independent Variable 3} \\
\hline & Medical Device Market & $\begin{array}{l}\text { In the medical device, this is especially } \\
\text { imperative in light of the fact that the } \\
\text { purchaser's side speaks to the } \\
\text { accessibility of medical care and the } \\
\text { provider representatives loathe the }\end{array}$ \\
\hline
\end{tabular}




\begin{tabular}{lll}
\hline \hline & & $\begin{array}{l}\text { accessibility of the new therapeutic } \\
\text { innovations [2] }\end{array}$ \\
\hline 2. Health Care Providers & $\begin{array}{l}\text { Specialist companions have } \\
\text { commented that there might be human } \\
\text { services suppliers who bolster } \\
\text { torment" [44] }\end{array}$ \\
\hline 3. Regulations & $\begin{array}{l}\text { "This Article develops a method for } \\
\text { interpreting regulations and, more } \\
\text { generally" [45] }\end{array}$ \\
\hline \hline
\end{tabular}

B. Medical Device Figures

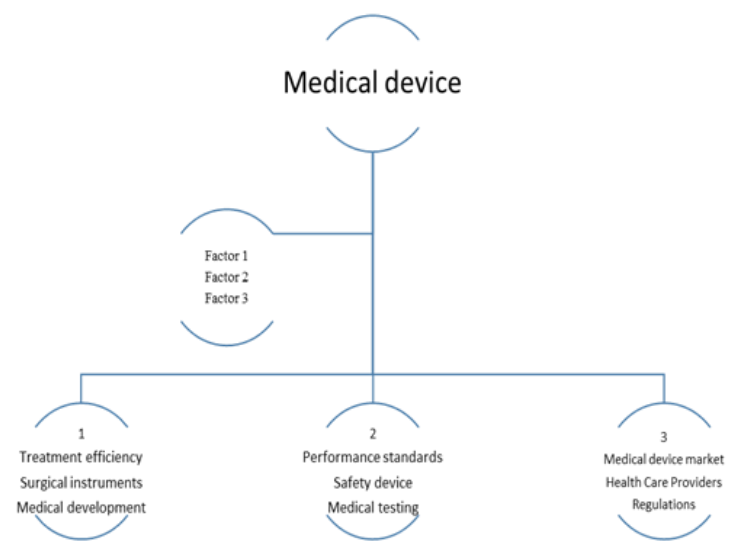

Fig.1. Factors 1, 2, 3 of each Independent Variable listed supports the medical device concept

The factors illustrated in Fig.1 support and emphasize the medical device's parts through its role and process. Increased reporting of antagonistic responses to medications and gadgets are indicated. Enhanced reporting of the antagonistic responses to drugs and other medical gadgets have been created through discovering approaches to support more reports from specialists and other wellbeing experts specifically to FDA, while most reports are presently made through producers [46]. As this article mentioned, Foote inspects the medical gadget industry from a down to earth and exhibit introduction. Her exchange is outfitted considerably more to gadget producers and to those in a well-being strategy who are worried with the (present and future) cost and the security issues of innovation in medication than to antiquarians intrigued by examinations between the restorative gadget industry and the historical backdrop of different business [47].

Moreover, according to Smith, who has been nearly observing the pattern, he has concluded that out-of-state offending parties make up around 93 for each penny of medication and therapeutic gadgets. Cases documented in Minnesota's state and government courts since elected court filings that went online there in May 2004 [48]. In addition, the article describes the development of these norms and methods and, all the while, looks for to distinguish the powers that have affected this advancement.

Part I depicts the improvements of the present day administration for managing drugs. Part II delineates the later development of the administration for medical gadgets. Part
III finishes up by investigating the major proposition for statutory changes currently being discussed [49]. To figure out if the reason for this method of reasoning may comparably apply to the flush water utilized amid endoscope reprocessing, the FDA's restorative gadget reporting database was reviewed and the endoscope reprocessing writing, and different sources were also evaluated. The consequences of this audit showed that the nonsocial flare-ups connected to endoscopes debased with gram-negative microscopic organisms have been every now [50].

The lactogenic transmissions of these maladies by means of a defiled restorative gadget is viewed as uncommon. Despite this finding and position, there have been some cases where such occurrences have been reported. In a trial case, the transmission of the malady was seen in spite of cleaning. In addition, cleaning of the restorative gadget was done with formaldehyde. Clinically, 2 instances of TSEs (Transmissible Spongiform Encephalopathies) have been affirmed in which transmission of the malady was due to the utilization of embedded profundity cathodes that had been already utilized on a patient with CJD (Creutzfeldt-Jakob Disease) and that were deficiently sterilized by cleaning with benzene and sanitizing with $70 \%$ liquor what's more, formaldehyde [51].

At the end, the Therapeutic Devices Act gave the FDA power and authority to request a reviews of gadgets, to oblige makers to tell patients about gadget problems, and to set up registries of patients who have "basic gadgets" in order for patients who have lasting inserts or other life-supporting gadgets to be instantly informed about issues. Medical caretakers should be completely educated about the safe utilization of the gadgets. For example, the focal venous catheter keeping in mind the end goal to minimize chance and advance patient wellbeing [52].

\section{Research Findings}

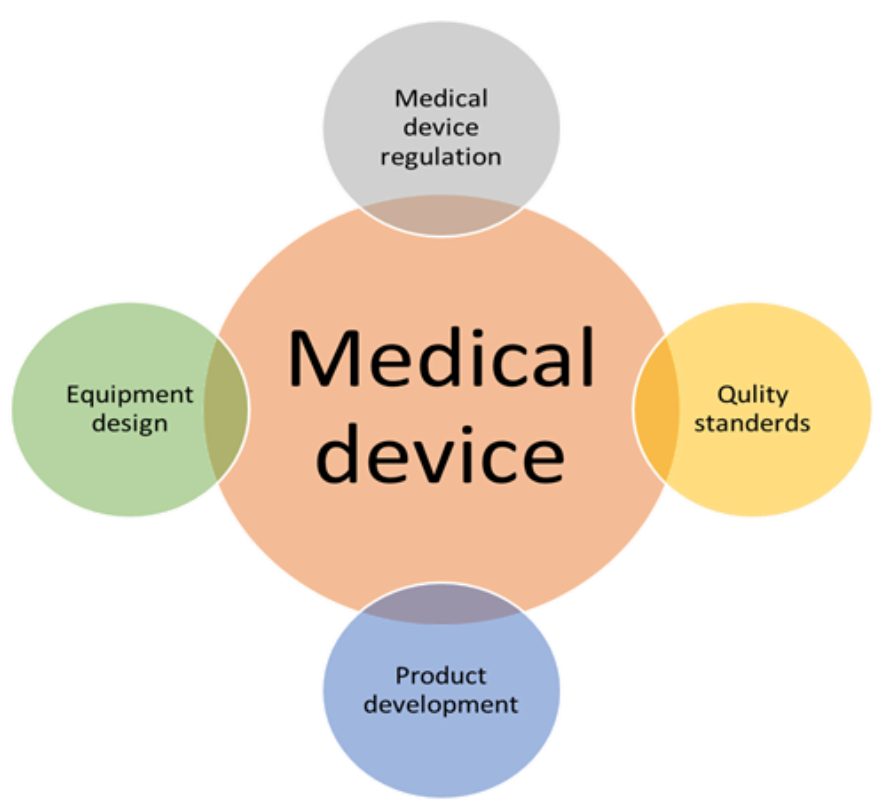

Fig.2. Additional Independent Variables

Thanks to the continuous development of medical devices, hospitals have managed to save more lives with fewer errors. The advancements sustained through the use of Medical devices has allowed doctors to rely on their results when diagnosing their patients. The production of medical device 
has increased and has drawn attention to big corporation to invest in this field. Governments issue an act toward the manufacturing of medical devices to ensure its safety where it gives the FDA further authority to order recalls of devices, to require manufacturers to notify patients about device problems, and to set up registries of patients who have "critical devices" so that patients who have permanent implants or other life-supporting devices will be promptly notified about problems [52].

\section{Contribution and New Insight}

In the course of my research, I had located pertinent information regarding the emergence, structure and operations of the medical device industry from the timeline in which it was created through its subsequent years of growth and progress. In the business of medical devices new advances also have emerged. Medical devices logically have been touted as a successful approach to deal with increase of healthcare expenses while upgrading the quality of care.

Through observations of manufacturing conglomerates similar to Medtronic and Johnson and Johnson, other manufacturers were emphasizing on locating incremental headways for improvements and enhancements to their present processes. There have been dangerous precedencies that have been followed for which they are seeking to avoid. In order to initiate change, they have looked to specialized business visionaries like John Simpson along with past delegates of industry officeholders like the Advanced Cardiovascular Systems alums, and serial business visionaries who discovered distinctive associations. They have also looked to people from the outside of the business who had promising considerations.

Restorative gadget firms make and promote a variety of innovative devices for the use by specialists in the midst of cardiovascular, neurological, and diverse sorts of therapeutic frameworks. These devices consolidate scientific rigging like Computerized Axial Tomography (CAT), helpful contraptions, pace-makers, and are also used in the course of other uses aside from processes directly involving surgical instruments such as endoscopes. Things are regularly promoted besides vended particularly to therapeutic specialists to source associations. In addition, I had explained more in a few graphs on how we were thousands of corporations investing in this field of business [53].

\section{CONCLUSION}

The creation and the emergence of Medical devices speak to a large, and developing consumption for social insurance suppliers and healthcare providers. These suppliers are under pressure to contain costs in an industry that confronts multiple money related difficulties and series of financial pressures and constraints.

One way to deal with slicing costs has been to sanitize and revamp gadgets that are marked for a solitary utilization. This practice, known as reprocessing, has been concentrated on from moral and specialized points of view yet moderately little exertion has been used to analyze the monetary and operational parts of this essential issue. There are questions as to whether reprocessing represents a danger and a hazard to patients who are undergoing treatments involving the uses of these devices.
An MDP (Markov Decision Process) model was defined to apply the time-tried standards of gear support research to the advantages and the drawbacks that are associated with the choices of whether a social insurance supplier or a healthcare provider ought to utilize new or revamped gadgets. The ideal strategy was described by finding the correct purpose of lack of concern amongst "supplant" and "repair" choices. The model was then stretched out to a POMDP (Partially Observed Markov Decision Process), representing the way that the genuine condition of the gadget may not be effortlessly watched.

Illustration applications covering an extensive variety of device sorts were introduced. These cases clarify how device states can be characterized, and illustrate the potential degrees and series of investigations that are conceivable with the model, and they exhibit how the model could be put into practice. The illustrations demonstrate that if the (MDP) displays show that reprocessing is not ideal, then it is not justified in the (POMDP) situation. As anyone might expect, when conclusive data about the genuine state is accessible, the ideal (POMDP) strategy is very common. Along these lines, social insurance suppliers and healthcare providers require ideal answers for the (POMDP) for all devices - the abnormal state comes about gave by the totally noticeable (MDP) can be utilized to distinguish classes or groups of items for which reprocessing is not practical. This finding speaks to the principle of the administrative understanding of the model: Perfect data about the device states and additionally contamination hazard is by and large not important to settle on a cool headed choice with respect to reprocessed devices. Appraisal of the disease hazard is testing and expensive, so eliminating selective device sorts from thought can spare considerable assets. Making an adaptable system with which medical services suppliers can play out these sorts of appraisals for particular gadget sorts are the principle commitment of the paper. To this point, most examinations of the vital social insurance and healthcare provider issue has been in extremely broad terms and has fundamentally been determined. Future research in a few zones would be helpful. All things considered, it is trusted that the data and the findings uncovered by this paper will provide an incentive to social insurance suppliers and healthcare providers to discover approaches to find out the applicable information and utilize the system and settle on the best choices that are beneficial to the patient and the provider.

\section{REFERENCES}

[1] Leahey, M.B., "FDA is gold standard of review," BMJ: British Medical Journal, 2010. 341(7785): pp. 1235-1235.

[2] Grennan, M., "'Price Discrimination and Bargaining: Empirical Evidence from Medical Devices," The American Economic Review, 2013. 103(1): p. 145-177.

[3] Makow, L.S., "Medical Device Review at the Food and Drug Administration: Lessons from Magnetic Resonance Spectroscopy and Biliary Lithotripsy," Stanford Law Review, 1994. 46(3): p. 709-746.

[4] Sloan, T., "First, Do No Harm? A Framework for Evaluating New versus Reprocessed Medical Devices," The Journal of the Operational Research Society, 2010. 61(2): p. 191-201.

[5] Polisena, J., et al., "Reprocessing and Reuse of Single;Use Medical Devices: A National Survey of Canadian Acute; Care Hospitals," Infection Control and Hospital Epidemiology, 2008. 29(5): p. 437-439.

[6] Bright, R.A., "The Conference on the Epidemiology of Medical Devices in Women," Epidemiology, 2002. 13(3): p. S1-S9. 
[7] Chester, A.R., T.E. Hoyer, and A.A. Thomas, "Encouraging Medical Device Innovation: Reimbursement Problems and New Policies,' Public Health Reports (1974-), 1996. 111(5): p. 468-470.

[8] Charatan, F., "US Confirms Federal Authority for Safety of Medical Devices," BMJ: British Medical Journal, 2008. 336(7642): p. 470-470

[9] Ludgate, S., "MRHA works hardlto ensure that medical devices work and are safe," BMJ: British Medical Journal, 2012. 344(7848): p. 3030.

[10] McKay, N.L., "Industry Effects of Medical Device Regulation: The Case of Diagnostic Imaging Equipment," Journal of Policy Analysis and Management, 1986. 6(1): p. 35-44.

[11] Nahnhauer, A. and W. Kaesbach, "Reimbursement of Medical Devices in Germany," Health Economics in Prevention and Care, 2000. 1(2): p. $140-145$.

[12] Spivak, J.M., "Regulation of Medical Devices," The Annals of the American Academy of Political and Social Science, 1972. 400: p. 82 94.

[13] Torrence, M.E., "Data Sources: Use in the Epidemiologic Study of Medical Devices," Epidemiology, 2002. 13(3): p. S10-S14.

[14] Gornall, J., "Medical Device or Consumer Product?" BMJ: British Medical Journal, 2012. 345(7876): p. 22-22.

[15] Ecchia, G. and L. Lambertini, "Minimum Quality Standards and Collusion," The Journal of Industrial Economics, 1997. 45(1): p. 101 113.

[16] Ronnen, U., "Minimum Quality Standards, Fixed Costs, and Competition," The RAND Journal of Economics, 1991. 22(4): p. 490 504

[17] Boom, A., “Asymmetric International Minimum Quality Standards and Vertical Differentiation," The Journal of Industrial Economics, 1995. 43(1): p. 101-119.

[18] Kluger, B.D., "Implications of Quality Standard Regulation for Multiproduct Monopoly Pricing," Managerial and Decision Economics, 1989. 10(1): p. 61-67.

[19] Gross, P.A., et al., "Quality Standard for the Treatment of Bacteremia," Clinical Infectious Diseases, 1994. 18(3): p. 428-430.

[20] Hansen, J., et al., "Economic Integration and Quality Standards in a Duopoly Model with Horizontal and Vertical Product Differentiation," Journal of Economic Integration, 2006. 21(4): p. 837-860.

[21] McFarland, R.A., Human Biology, 1955. 27(3): p. 248-249.

[22] Ellis, W.S., Human Biology, 1967. 39(2): p. 205-207.

[23] Snyder, R.G., American Anthropologist, 1967. 69(5): p. 539-540.

[24] Clark, C.C., The Physical Measure of Man. Science, 1966. 154(3749): p. $638-638$.

[25] Browne, R.C., British Journal of Industrial Medicine, 1954. 11(4): p. 308-308.

[26] Ryan, T.A., Industrial and Labor Relations Review, 1955. 8(3): p. 452 452.

[27] Nash, B., Product Development. Journal of Marketing, 1937. 1(3): p. 254-262.

[28] Hoopes, D.G., “Considering Risk in Product Development" Risk Management, 2001. 3(2): p. 7-15

[29] Meyer, M.H. and D. Arthur, "Product Development for Services," The Academy of Management Executive (1993-2005), 1999. 13(3): p. 64 76

[30] McCarthy, E.J., "Organization for New-Product Development?," The Journal of Business, 1959. 32(2): p. 128-132.
[31] Ittner, C.D. and D.F. Larcker, "Product Development Cycle Time and Organizational Performance," Journal of Marketing Research, 1997. 34(1): p. 13-23.

[32] Sellstedt, B. and B. Naslund, "Product Development Plans," Operational Research Quarterly (1970-1977), 1972. 23(4): p. 497-510

[33] Sorenson, C. and M. Drummond, "Improving Medical Device Regulation: The United States and Europe in Perspective," The Milbank Quarterly, 2014. 92(1): p. 114-150.

[34] Rettig, R.A., "The Federal Government and Medical Technology: Crossing Policy and Management Thresholds," Policy Sciences, 1980 11(3): p. 343-356.

[35] Cohen, D., "Reply to DePuy Criticisms," BMJ: British Medical Journal, 2012. 344(7856): p. 31-32.

[36] Brennan, B.J., "The Need for Cooperation of Industry, Physicians and Government in Regulation of Medical Devices," The Business Lawyer 1970. 26(2): p. 365-376.

[37] Ein-Dor, P. and E. Segev, "Strategic Planning for Management Information Systems," Management Science, 1978. 24(15): p. 16311641.

[38] Huff, C.B., et al., "Study of Ultraviolet Disinfection of Water and Factors in Treatment Efficiency," Public Health Reports (1896-1970) 1965. 80(8): p. 695-705

[39] Singh, M., "Surgical Instruments Industry at Jalandhar: A Case Study," Economic and Political Weekly, 2002. 37(31): p. 3298-3304.

[40] Mackay, J., et al., "Voluntary Service Overseas," The British Medical Journal, 1977. 1(6060): p. 572-573.

[41] Aizawa, M., "IFC's New Sustainability Performance Standards," Natural Resources \& Environment, 2006. 21(1): p. 62-70.

[42] Robinson, J.S., H.T. Davenport, and B.M. "Wright, Simple OxygenFailure Safety Device," The British Medical Journal, 1974. 4(5941): p 407-407.

[43] Oster, E., I. Shoulson, and E.R. Dorsey, "Optimal Expectations and Limited Medical Testing: Evidence from Huntington Disease," The American Economic Review, 2013. 103(2): p. 804-830.

[44] Hamond-Gallardo, N., "More on Torture," The American Journal of Nursing, 2005. 105(3): p. 15-15.

[45] Stack, K.M., "Interpreting Regulations," Michigan Law Review, 2012. 111(3): p. 355-421.

[46] "FDA Action Plan Charts Priorities, Directions for the Future," Public Health Reports (1974-), 1985. 100(6): p. 672-673.

[47] Buchanan, R.A., The Business History Review, 1993. 67(3): p. 492 493.

[48] Hansen, M., "Lawsuits Travel Up North: Land of Ten Thousand Lakes is flooded with thousands of out-of-state filings," ABA Journal, 2007. 93(12): p. 16-17

[49] Merrill, R.A., "The Architecture of Government Regulation of Medical Products," Virginia Law Review, 1996. 82(8): p. 1753-1866.

[50] Muscarella, L.F., "Application of environmental sampling to flexible endoscope reprocessing: the importance of monitoring the rinse water," Infection Control and Hospital Epidemiology, 2002. 23(5): p. 285-289.

[51] Gerald, M. and P. Burke, "The Challenge of Prion Decontamination," Clinical Infectious Diseases, 2003. 36(9): p. 1152-1154.

[52] Murray, E.W., "From FDA Nurses: Probing the Safety of Central Venous Catheters," The American Journal of Nursing, 1993. 93(5): $p$ $72-76$

[53] Chatterji, A.K., "Spawned with a Silver Spoon? Entrepreneurial Performance and Innovation in the Medical Device Industry," Strategic Management Journal, 2009. 30(2): p. 185-206. 